\title{
COLABORAÇÃO OPEN BIM: CAPACITAÇÃO DE PROFISSIONAIS PARA TROCAS DE MODELOS
}

Modalidade: Experiência de ensino-aprendizagem BIM realizadas

\section{REALIZAÇÃO DO TREINAMENTO}

\section{Treinamento de Colaboração OPEN \\ BIM possui 12h e é dividido em 4 partes. A primeira parte trata dos conceitos fundamentais sobre OPEN BIM. Apresenta um fluxo de trabalho OPEN BIM simplificado e aborda a importância dos protocolos para a interoperabilidade desenvolvidos pela buildingSMART e apresenta de forma básica IFD (International Framework for Dicionaries), IDM (Informationa Delivery Manual), MVD (Model View Definition) e IFC (Industry Foundation Class).}

Figura 1: Fluxo Colaboração OPEN BIM Simplificado
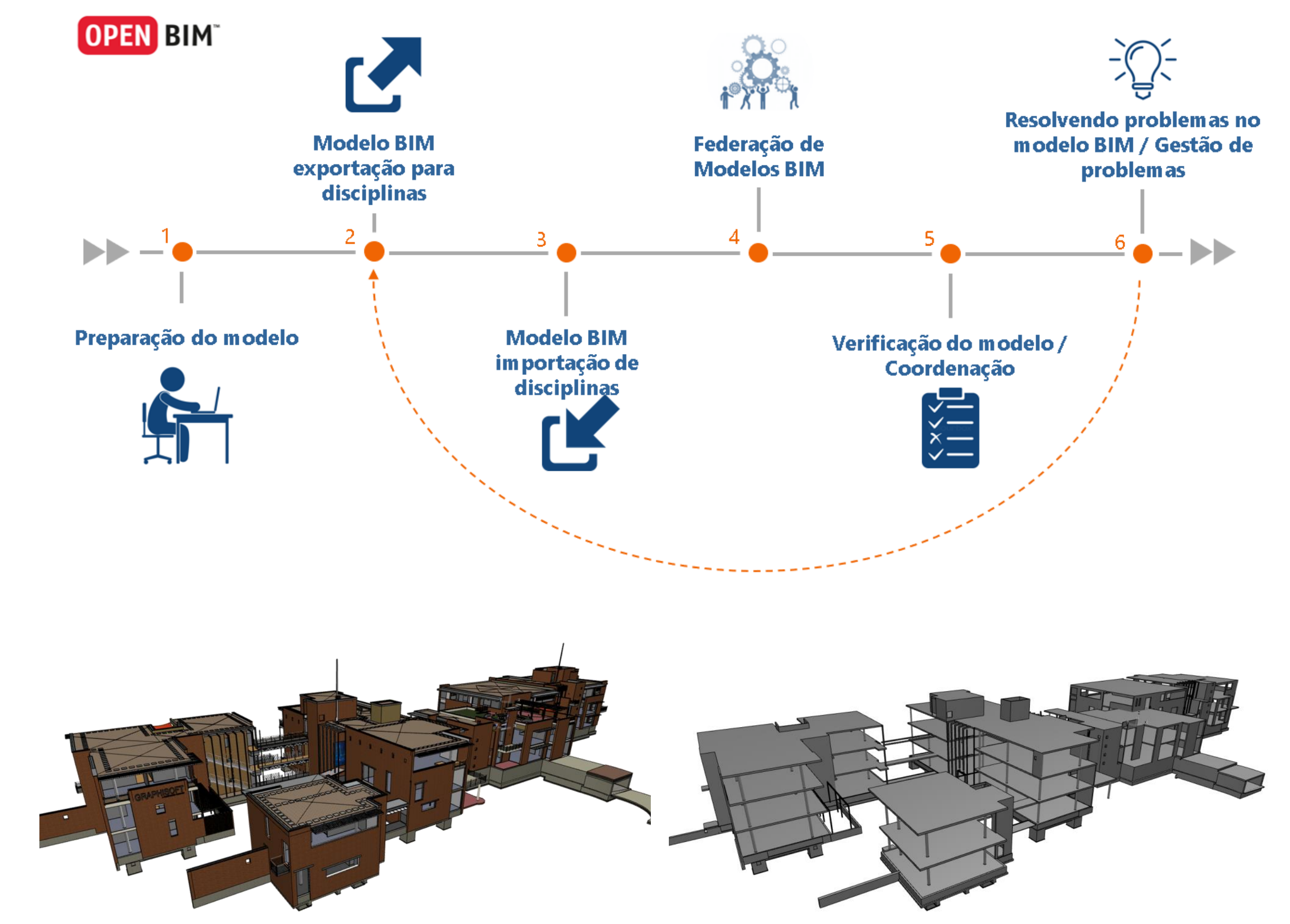

Figuras 3: Modelo da Arquitetura

Figuras 4: Modelo da Estrutura
A segunda parte aborda as questões relacionadas ao preparo do modelo para a colaboração e a importância do sistema de classificação para a troca de informações através de modelos. Já a terceira parte mostra como regular um tradutor IFC para a exportação do projeto. Por fim, a última parte trata do processo de importação e as boas práticas para uma efetiva federação dos modelos. Mostra como fazer o controle de versões de modelo IFC para uma integração de projetos com qualidade.

\section{LIÇÕES APRENDIDAS}

Segundo avaliação realizada pelos alunos após a conclusão do TCOB, 0 programa proposto foi adequado em relação às necessidades e expectativas, assim como o material de apoio para 0 desenvolvimento do conhecimento foi relevante. $77 \%$ dos alunos consideram que a duração do curso foi adequada. Dentre os pontos positivos apontados destacam-se os fundamentos sobre BIM e o esclarecimento de conhecer as
Figura 2: Gerenciamento de Informações do Modelo BIM
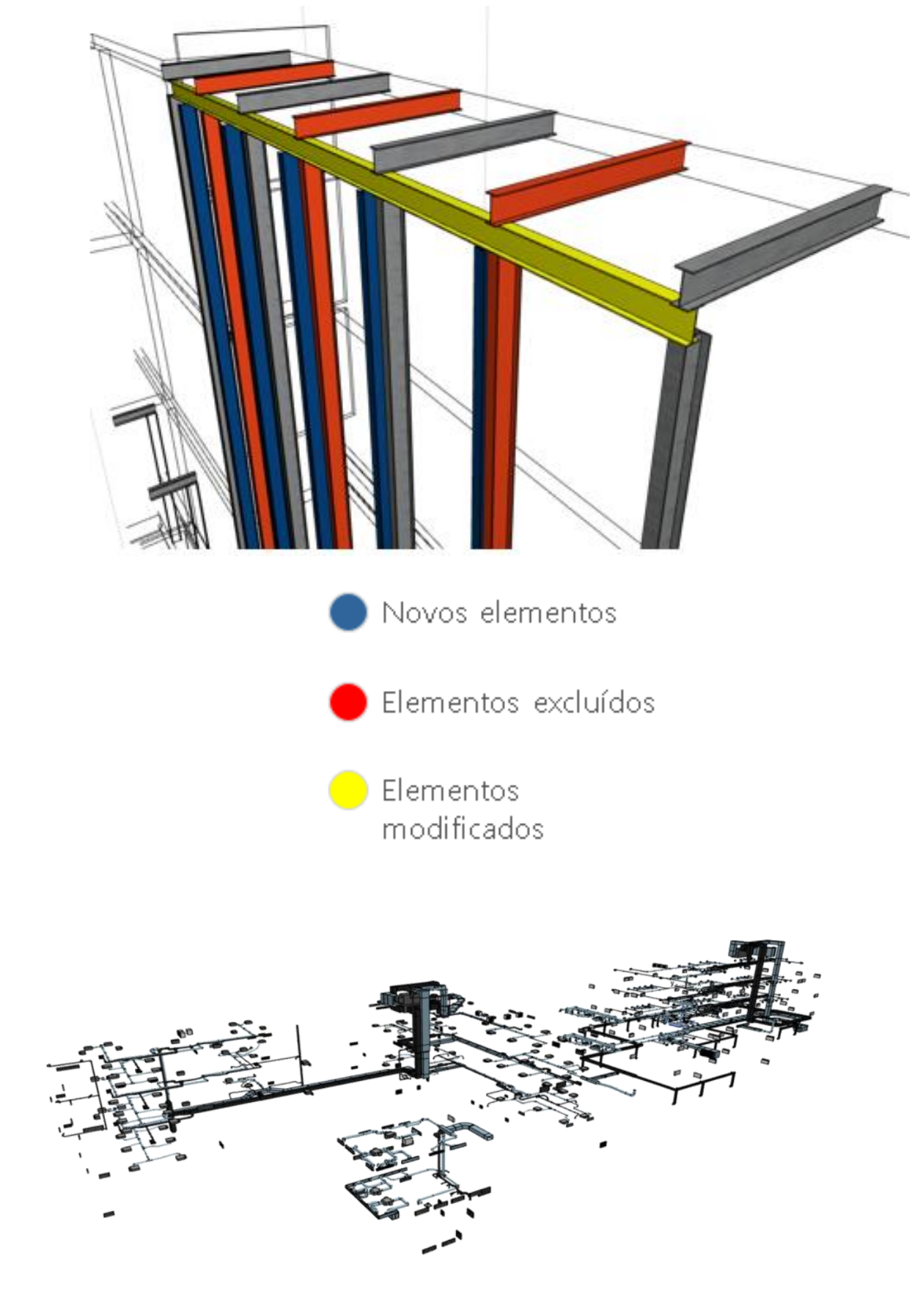

Figuras 5: Modelo MEP aplicações do IFC e como o configurar adequadamente. Dentre os pontos negativos, os alunos apontaram a necessidade de mais tempo para colocar em prática diversas possibilidades de configuração dos tradutores IFC. Ao longo das aulas, muito se discutiu sobre os acordos entre os projetistas para uma interoperabilidade eficiente, evidenciando a importância dos protocolos de troca de informações através de modelos levantadas na primeira parte da aula.
Eduardo R. dos Santos

1- PROARQ FAU UFRJ/D5, eduardo.ribeiro@fau.ufrj.br

\section{INTRODUÇÃO}

0 presente trabalho tem como objetivo apresentar a experiência desenvolvida em dois Treinamentos de Colaboração OPEN BIM (TCOB) realizado pela Graphisoft Brasil e ministrado pelo autor nos meses de novembro de 2020 e março de 2021 para 44 profissionais de arquitetura e engenharia. 0 TCOB foi desenvolvido pela Graphisoft através do Programa Educacional da própria empresa (Graphisoft Learn) com o objetivo de capacitar profissionais envolvidos nos processos de projeto nas boas práticas para a colaboração através de modelos de informação. Além das questões relacionadas a ferramenta Archicad no processo de interoperabilidade, este treinamento aborda também assuntos pertencentes a organização dos processos, da importância das políticas através do desenvolvimento dos protocolos para uma troca da informação eficiente.

\section{AGRADECIMENTOS}

0 presente trabalho foi realizado com apoio da Graphisoft Brasil, Graphisoft HG, PROARQ/UFRJ e CAPES 